\title{
A retrospective analysis of intensive care unit patients during the pandemic period
}

\author{
Canakci $\mathrm{E}^{1}$, Kaya $\mathrm{M}^{2}$, Karatas $\mathrm{A}^{3}$ \\ Ordu University, School of Medicine, Department of Anesthesiology and Reanimation, Training \\ and Research Hospital, Ordu, Turkey. canakciebru@gmail.com
}

\begin{abstract}
BACKGROUND: It is essential to understand well the prognosis and clinical findings for the early diagnosis and treatment of COVID-19 patients. We aimed to evaluate the laboratory parameters, risk factors, and success in predicting mortality in COVID-19 patients admitted to our hospital's intensive care units (ICUs). METHODS: Levels of procalcitonin, ferritin, D-dimer, CRP and albumin measured on days 1 and 7 were recorded. Patients were divided into two groups as non-survivors and patients, who were discharged from ICUs. The predictive values of laboratory parameters in predicting COVID-19 mortality were investigated. RESULTS: A statistically significant difference was detected between the two groups in the mean values of all laboratory parameters tested on days 1 and 7, including D-dimer, procalcitonin, CRP, WBC, ferritin (excluding only D-dimer levels and WBC counts on day $1 ; p=0.061$ and $p=0.243$, respectively) $(p<0.001, p<0.001$, $p<0.001, p=0.013, p<0.001, p<0.001, p<0.001, p<0.001, p<0.001, p<0.001$; respectively).

CONCLUSION:. It can be argued that procalcitonin, ferritin, and D-dimer can be guiding parameters in predicting mortality in COVID-19 because their levels were found to be significantly higher in non-survivors. D-dimer, procalcitonin, and ferritin showed an almost high level of sensitivity and specificity in predicting mortality (Tab. 5, Fig. 3, Ref. 19). Text in PDF www.elis.sk

KEY WORDS: COVID-19 pandemic, intensive care, mortality, laboratory parameters.
\end{abstract}

\section{Introduction}

SARS-CoV-2 has spread to Europe and America in a very short time after the occurrence of the first COVID-19 case in Wuhan in December 2019. The first COVID-19 case was detected in our country on March 10, 2020, shortly before the declaration of COVID-19 as a pandemic by the World Health Organization (WHO) (1). More than 25 million cases of COVID-19 and over 845,000 associated deaths were reported in the first eight months (2). The mortality rate of COVID-19 has been shown to vary by country, depending on health infrastructure and demographic differences such as age distribution. While the crude death rate in China was $2.3 \%$, it was determined as $14.8 \%$ in individuals aged 80 years or older. In Italy, one-fourth of the population consists of individuals aged 65 years or older and the crude mortality rate of $5 \%$ was found to be $20 \%$ in cases of patients aged over 80 years (3). SARS-CoV-2 causing COVID-19 is phylogenetically

${ }^{1}$ Ordu University, School of Medicine, Department of Anesthesiology and Reanimation, Ordu, Turkey, ${ }^{2}$ Ordu University, Training and Research Hospital, Clinic of Family Medicine, Ordu, Turkey, and ${ }^{3}$ Ordu University, School of Medicine, Department of Internal Medicine, Division of Nephrology Ordu, Turkey

Address for correspondence: E. Canakci, MD, Ordu University, School of Medicine, Department of Anesthesiology and Reanimation, Training and Research Hospital, Bucak Town, Nefs-i Bucak Street, Ordu, Turkey. Phone: +90.532 .2651687$ similar to SARS-CoV causing severe acute respiratory syndrome (SARS). SARS-CoV-2 is an enveloped $\beta$-coronavirus. Although the respiratory system is the portal of entry of SARS-CoV-2 into the body, COVID-19 is considered a multisystem disease because the disease affects many organs. It is thought that the resulting endothelial dysfunction is responsible for the pathophysiology of the disease. Apart from respiratory system findings, multisystem findings such as neurological, cardiovascular, and gastrointestinal symptoms and signs can be also detected (4).

This study aimed to evaluate the clinical characteristics, laboratory and imaging findings, and prognosis of hospitalized COVID-19 patients, who were admitted to the Training and Research Hospital of Ordu University for treatment and follow-up during the COVID-19 pandemic period.

\section{Methods}

We applied to the local ethics committee for permission to begin our study after receiving approval from the Turkish Ministry of Health Clinical Research Committee. The approval from Ordu University's Clinical Research Local Ethics Committee was obtained with decision number 2021/65, and date 18.03.2021. This is a retrospective cohort study. No financial support was received for conducting the study. The patients who were admitted to the pandemic intensive care units (ICUs) in Ordu University Training and Research Hospital in the period between March 11, 2020 and March 11, 2021, were included in our study. The diagnosis 
805-810

of COVID-19 was confirmed in accordance with the Ministry of Health's COVID-19 scientific committee diagnostic guidance.

A total of 195 COVID-19 patients registered on the 'SARUS Software' database in the designated pandemic ICUs in our hospital were included in the study. Patients' levels of procalcitonin, ferritin, D-dimer, CRP, and albumin obtained on days 1 and 7 of admission were recorded. Our research included cases diagnosed with COVID-19 and hospitalized in one of our designated pandemic ICUs for more than 7 days.

The results of the laboratory parameters were evaluated to determine whether they could be the risk factors for COVID-19 mortality. Patients included in the study were divided into two groups as those who were discharged from ICUs and those who died.

Included were all ICU patients diagnosed with COVID-19 in accordance with the Ministry of Health's COVID-19 diagnostic guidance, and were older than 18 years, had adequate available data, and received invasive or non-invasive mechanical ventilation support (NIMV), underwent mask with reservoir treatment, or received high-flow oxygen supply. Patients were included in the study regardless of whether they were intubated or not. Patients younger than 18 years, who did not have a confirmed COVID-19 diagnosis, were hospitalized in the pandemic inpatient units of our hospital, and patients with inadequately available data were excluded from the study.

\section{Statistical methods}

The data were analyzed using IBM SPSS V23. The conformity of the data to normal distribution was examined by the Kolmogorov-Smirnov test. The Chi-square test and Fisher's exact test were used to compare categorical variables between the groups. Mann-Whitney U test and the independent two-sample t-test were used to compare non-normally distributed data and normally distributed data, respectively, between the groups. For intragroup comparisons along the time course, the Wilcoxon test and the paired samples t-test were used to compare the non-normally distributed and normally distributed data, respectively. The cut-off values for the parameters obtained from the non-survivor ICU patients were determined using ROC analysis. Analysis results were presented as mean \pm standard deviation and median (minimum-maximum) for quantitative data. Categorical data were presented as frequency (percentage). The level of significance was taken as $\mathrm{p}<0.050$.

\section{Results}

The demographic data of the patients, who were hospitalized in the designated pandemic ICUs of our hospital in the period between March 11, 2020 and March 11, 2021 are presented in Table 1.
There were no statistically significant differences in the distribution of categorical variables between non-survivors and patients discharged from ICU ( $\mathrm{p}>0.050)$.

The comparison of the two groups as for the variable of age is presented in Table 2 .

The median age was different between non-survivors and patients discharged from ICU $(p<0.001)$. The median age of discharged patients was 65.00 years, while the median age of nonsurvivors was 77.00 years.

Intergroup and intragroup comparisons of the laboratory parameters are presented in Table 3.

Median D-dimer values obtained on day 7 were different between non-survivors and discharged patients $(p<0.001)$. The median values in discharged patients and non/survivors were 0.55 and 2.48 , respectively. D-dimer values showed differences along the time course in non-survivors $(\mathrm{p}<0.001)$. While the day-1 median value was 0.72 , the day- 7 median value was 2.48 . The day- 1 median values of procalcitonin levels were different between the patients discharged from ICUs and those who died $(\mathrm{p}<0.001)$. While the median value in discharged patients was 0.10 , in non-survivors, it was 0.43 . The day- 7 median procalcitonin values were different between the patients discharged from ICUs and those who died ( $p$ $<0.001$ ). The median value in discharged patients was 0.07 , while in non-survivors, it was 0.74 . Procalcitonin values were different along the time course in the patients discharged from ICUs ( $p=$ 0.023 ). While the day-1median value was 0.10 , the day- 7 median was 0.07 . Procalcitonin values differed along the time course in non-survivors $(\mathrm{p}=0.002)$. While the day- 1 median level was 0.43 , the day-7 median level was 0.74 . The day-1 median CRP values was different between the discharged patients and non-survivors $(p=0.013)$. While the median value was 4.85 in discharged patients, in non-survivors, it was 7.84. The day-7 median CRP values were different between discharged patients and non-survivors ( $p$ 
Tab. 3. Intergroup and intragroup comparisons of the laboratory parameters of ICU patients.

\begin{tabular}{|c|c|c|c|c|}
\hline & Discharged & Died & Statistical test & $\mathrm{p}$ \\
\hline D-dimer Day 1 & $\begin{array}{c}1.35 \pm 1.97 \\
0.45(0.03-8.33)\end{array}$ & $\begin{array}{c}1.59 \pm 1.97 \\
0.72(0.09-8.06)\end{array}$ & $\mathrm{U}=3,389$ & 0.061 \\
\hline D-dimer Day 7 & $\begin{array}{c}1.18 \pm 1.66 \\
0.55(0.09-7.77)\end{array}$ & $\begin{array}{c}3.30 \pm 3.31 \\
2.48(0.14-20.32)\end{array}$ & $\mathrm{U}=1,774.5$ & $<0.001$ \\
\hline $\begin{array}{l}\text { Statistical test } \\
\mathrm{p}\end{array}$ & $\begin{array}{c}\mathrm{Z}=-0.481 \\
0.631\end{array}$ & $\begin{aligned} Z & =4.516 \\
& <\mathbf{0 . 0 0 1}\end{aligned}$ & & \\
\hline Procalcitonin Day1 & $\begin{array}{c}0.91 \pm 3.23 \\
0.10(0.03-28.80)\end{array}$ & $\begin{array}{c}4.04 \pm 11.26 \\
0.43(0.04-55.70)\end{array}$ & $\mathrm{U}=1,725.5$ & $<0.001$ \\
\hline Procalcitonin Day 7 & $\begin{array}{c}0.72 \pm 3.08 \\
0.07(0.02-28.80)\end{array}$ & $\begin{array}{c}6.68 \pm 13.74 \\
0.74(0.04-61.20)\end{array}$ & $\mathrm{U}=1,044$ & $<0.001$ \\
\hline $\begin{array}{l}\text { Statistical test } \\
\mathrm{p}\end{array}$ & $\begin{array}{c}\mathrm{Z}=-2.268 \\
\mathbf{0 . 0 2 3}\end{array}$ & $\begin{array}{c}\mathrm{Z}=-3.115 \\
\mathbf{0 . 0 0 2}\end{array}$ & & \\
\hline CRP Day 1 & $\begin{array}{c}7.27 \pm 8.54 \\
4.85(0.11-48.27)\end{array}$ & $\begin{array}{c}10.11 \pm 9.45 \\
7.84(0.12-36.58)\end{array}$ & $\mathrm{U}=3,362.5$ & 0.013 \\
\hline CRP Day 7 & $\begin{array}{c}3.75 \pm 4.85 \\
1.85(0.07-25.58)\end{array}$ & $\begin{array}{c}13.45 \pm 11.63 \\
10.71(0.09-51.86)\end{array}$ & $\mathrm{U}=1,706.5$ & $<0.001$ \\
\hline $\begin{array}{l}\text { Statistical test } \\
\mathrm{p}\end{array}$ & $\begin{aligned} Z & =4.653 \\
& <\mathbf{0 . 0 0 1}\end{aligned}$ & $\begin{array}{c}Z=-2.248 \\
\mathbf{0 . 0 2 5}\end{array}$ & & \\
\hline Albumin Day 1 & $\begin{array}{c}3.51 \pm 0.60 \\
3.50(1.90-4.90)\end{array}$ & $\begin{array}{c}3.04 \pm 0.59 \\
3.00(1.50-4.30)\end{array}$ & $\mathrm{t}=3.936$ & $<0.001$ \\
\hline Albumin Day 7 & $\begin{array}{c}3.25 \pm 0.57 \\
3.20(2.10-4.70) \\
\end{array}$ & $\begin{array}{c}2.60 \pm 0.66 \\
2.70(1.40-3.90) \\
\end{array}$ & $\mathrm{t}=4.171$ & $<0.001$ \\
\hline $\begin{array}{l}\text { Statistical test* } \\
\mathrm{p}\end{array}$ & $\begin{array}{c}\mathrm{t}=0.672 \\
\mathbf{0 . 5 0 9}\end{array}$ & $\begin{array}{c}\mathrm{t}=3.722 \\
\mathbf{0 . 0 0 1}\end{array}$ & & \\
\hline WBC Day 1 & $\begin{array}{c}8,357.11 \pm 4,622.80 \\
7,185.00(2,010.00-33,580.00) \\
\end{array}$ & $\begin{array}{c}8,997.16 \pm 10,570.17 \\
6,910.00(450.00-8,0820.00) \\
\end{array}$ & $\mathrm{U}=3,851.5$ & 0.243 \\
\hline WBC Day 7 & $\begin{array}{c}9,057.19 \pm 4,211.96 \\
8,420.00(2,010.00-29,430.00)\end{array}$ & $\begin{array}{c}16,137.46 \pm 14,122.57 \\
14,470.00(1,020.00-83,470.00)\end{array}$ & $\mathrm{U}=2,677.5$ & $<0.001$ \\
\hline $\begin{array}{l}\text { Statistical test } \\
\mathrm{p}\end{array}$ & $\begin{array}{c}\mathrm{Z}=-2.797 \\
\mathbf{0 . 0 0 5}\end{array}$ & $\begin{aligned} Z & =4.357 \\
& <\mathbf{0 . 0 0 1}\end{aligned}$ & & \\
\hline Ferritin Day 1 & $\begin{array}{c}452.52 \pm 824.68 \\
182.00(8.95-7,469.00) \\
\end{array}$ & $\begin{array}{c}1,402.42 \pm 3,935.53 \\
435.50(16.20-29,237.00)\end{array}$ & $\mathrm{U}=2,632$ & $<0.001$ \\
\hline Ferritin Day 7 & $\begin{array}{c}491.88 \pm 834.75 \\
246.50(12.40-7,469.00) \\
\end{array}$ & $\begin{array}{c}3,936.24 \pm 13,228.80 \\
998.50(23.65-100,000.00)\end{array}$ & $\mathrm{U}=1,517$ & $<0.001$ \\
\hline $\begin{array}{l}\text { Statistical test } \\
\mathrm{p}\end{array}$ & $\begin{array}{c}\mathrm{Z}=-1.27 \\
0.204\end{array}$ & $\begin{aligned} Z & =4.677 \\
& <\mathbf{0 . 0 0 1}\end{aligned}$ & & \\
\hline
\end{tabular}

Tab. 4. Descriptive statistics of quantitative parameters across both groups of ICU cases.

\begin{tabular}{lcc}
\hline & $\begin{array}{c}\text { Mean } \pm \text { standard } \\
\text { deviation }\end{array}$ & Median (min-max) \\
\hline D-dimer Day 1 & $1.43 \pm 1.97$ & $0.54(0.03-8.33)$ \\
D-dimer Day 7 & $1.90 \pm 2.55$ & $0.83(0.09-20.32)$ \\
Procalcitonin Day 1 & $2.05 \pm 7.40$ & $0.19(0.03-55.70)$ \\
Procalcitonin Day 7 & $2.97 \pm 9.21$ & $0.20(0.02-61.20)$ \\
CRP Day 1 & $8.25 \pm 8.94$ & $5.49(0.11-48.27)$ \\
CRP Day 7 & $7.08 \pm 9.09$ & $3.70(0.07-51.86)$ \\
Albumin Day 1 & $3.30 \pm 0.64$ & $3.25(1.50-4.90)$ \\
Albumin Day 7 & $2.92 \pm 0.69$ & $2.90(1.40-4.70)$ \\
Ferritin Day 1 & $767.46 \pm 2,394.57$ & $278.00(8.95-29,237.00)$ \\
Ferritin Day 7 & $1,652.09 \pm 7,839.56$ & $436.00(12.40-100,000.00)$ \\
\hline
\end{tabular}

$<0.001)$. The median value in the group of discharged patients was 1.85 , while in the group of non-survivors, it was 10.71. CRP values changed along the time course in patients discharged from ICUs $(\mathrm{p}<0.001)$. While the day- 1 median value was 4.85 , the day-7 median value was 1.85 . CRP values changed along the time course in non-survivors $(\mathrm{p}=0.025)$. While the day-1 median value was 7.84 , the day-7 median value was 10.71 .

The day-1 mean albumin values was different between discharged patients and non-survivors $(\mathrm{p}<0.001)$. While the mean value in discharged patients was 3.51, in non-survivors, it was 3.04. The day-7 mean value of albumin levels was different between the patients discharged from ICUs and those who died $(\mathrm{p}<0.001)$. While the mean value in the discharged patient group was 3.25 , in non-survivors, it was 2.60. Albumin values changed along the time course in non-survivors $(\mathrm{p}=0.001)$. While the day-1mean value was 3.04 , the day-7 mean value was 2.60 . The day-7 median WBC values were different between the discharged patients and non-survivors $(\mathrm{p}<0.001)$. While in the discharged patient group the median value was $8,420.00$, in the non-survivor group, it was $14,470.00$. WBC counts changed along the time course in discharged patients $(\mathrm{p}=0.005)$. While the day- 1 median value was $7,185.00$, the day-7 median value was $8,420.00$. WBC counts changed along the time course in non-survivors $(p<0.001)$. The 
Tab. 5. ROC analysis results.

\begin{tabular}{|c|c|c|c|c|c|c|c|c|}
\hline & Cut-off & AUC $(95 \% \mathrm{CI})$ & $\mathrm{p}$ & Sensitivity $(95 \% \mathrm{CI})$ & Specificity $(95 \% \mathrm{CI})$ & PPV & NPV & Accuracy \\
\hline D-dimer Day 1 & - & $0.583(0.5-0.666)$ & 0.061 & - & - & - & - & - \\
\hline D-dimer Day 7 & $>1.105$ & $0.782(0.714-0.849)$ & $<0.001$ & $0.738(0.631-0.845)$ & $0.728(0.65-0.806)$ & 0.594 & 0.842 & 0.731 \\
\hline Procalcitonin Day 1 & $>0.2035$ & $0.743(0.665-0.821)$ & $<0.001$ & $0.683(0.565-0.801)$ & $0.667(0.574-0.76)$ & 0.566 & 0.776 & 0.673 \\
\hline Procalcitonin Day 7 & $>0.2735$ & $0.824(0.76-0.889)$ & $<0.001$ & $0.733(0.621-0.845)$ & $0.768(0.685-0.851)$ & 0.625 & 0.826 & 0.755 \\
\hline Ferritin Day 1 & $>327.5$ & $0.66 \quad(0.577-0.744)$ & $<0.001$ & $0.629(0.509-0.749)$ & $0.624(0.539-0.709)$ & 0.457 & 0.772 & 0.626 \\
\hline Ferritin Day 7 & $>577$ & $0.811(0.746-0.877)$ & $<0.001$ & $0.742(0.633-0.851)$ & $0.736(0.659-0.813)$ & 0.588 & 0.852 & 0.738 \\
\hline
\end{tabular}

PPV - positive predictive value, NPV - negative predictive value

day-1 median value was $6,910.00$, while the day-7 median value was $14,470.00$. Day-1 median ferritin values was different between the groups of discharged patients and non-survivors $(p<0.001)$. While the median value in the discharged patient group was 182.00 , in non-survivors, it was 435.50 . The day-7 median ferritin values were different between discharged patients and non-survivors $(\mathrm{p}<$ 0.001 ). While in discharged patients, the median value was 246.50 , in non-survivors, it was 998.50 . Ferritin values changed along the time course in non-survivors $(\mathrm{p}<0.001)$. While the day-1 median value was 435.50 , the day-7 median value was 998.50 .

In non-survivors, the albumin levels were found to be low whereas D-dimer, procalcitonin, CRP, WBC, and ferritin levels were found to be high at all time points. There were significant differences in the levels of all variables between the two groups.

Descriptive statistics of quantitative parameters across both groups of COVID-19 cases admitted to ICUs are presented in Table 4.

ROC analysis results for day- 1 and day-7 values of D-dimer, procalcitonin, and ferritin are presented in Table 5.

When the day-7 cut-off value for D-dimer was taken as 1.105 , the obtained area under the curve (AUC) was 0.782 . This value was found to be statistically significant $(\mathrm{p}<0.001)$. Sensitivity and specificity were $73.8 \%$ and $72.8 \%$, respectively. When the day-1 cut-off value for procalcitonin levels was taken as 0.2035 , the obtained area under the curve (AUC) was 0.743 . This value was found to be statistically significant $(\mathrm{p}<0.001)$. Sensitivity and specificity were $68.3 \%$ and $66.7 \%$, respectively. When the day-7 cut-off value for procalcitonin levels was taken as 0.2735 , the obtained area under the curve (AUC) was 0.824 . This value was found to be statistically significant $(\mathrm{p}<0.001)$. Sensitivity and specificity values were found to be $73.3 \%$ and $76.8 \%$, respectively. When the day-1 cut-off value for the ferritin level was taken as 327.5, the obtained area under the curve (AUC) was 0.66. This value was found to be statistically significant $(\mathrm{p}<0.001)$. Sensitivity and specificity values were found to be $62.9 \%$ and $62.4 \%$, respectively. When the day-7 cut-off value for ferritin was taken as 577 , the obtained area under the curve (AUC) was 0.811 . This value was found to be statistically significant $(p<0.001)$. The obtained sensitivity and specificity values were $74.2 \%$ and $73.6 \%$, respectively.

It was proven that specificity and sensitivity of D-dimer, ferritin, and procalcitonin levels were sufficiently high to predict mortality.

The day-7 values of D-dimer, ferritin, and procalcitonin showed a higher level of specificity and sensitivity compared to

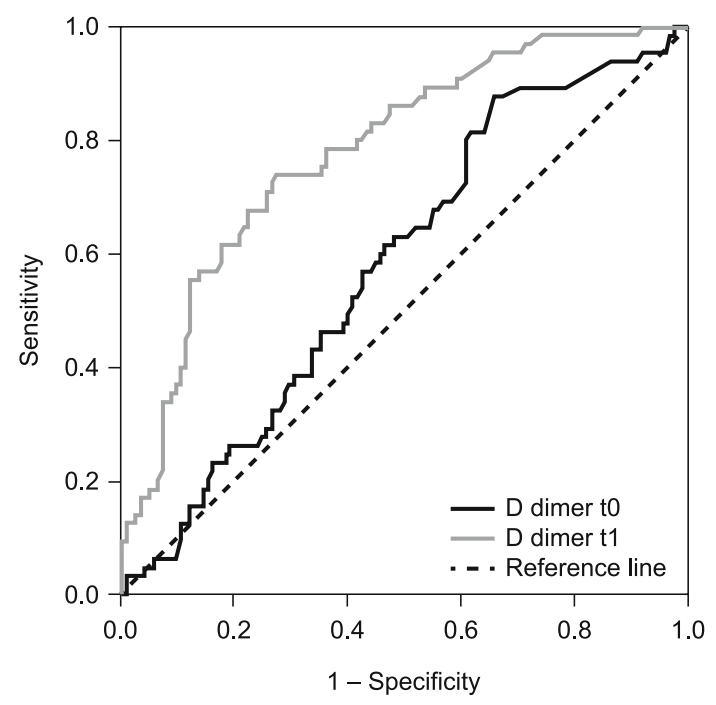

Fig. 1. ROC curve for D-dimer.

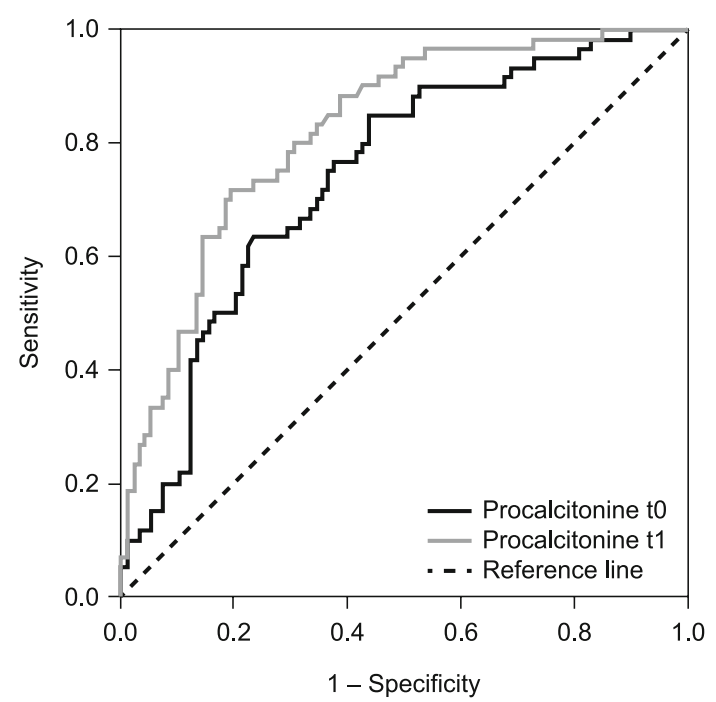

Fig. 2. ROC curve for Procalcitonin.

the day-1 values. The sensitivity and specificity of D-dimer, procalcitonin, and ferritin levels were found to be in range of $70 \%$ to $76 \%$. In this context, it can be argued that D-dimer, procalcitonin, and ferritin levels show a sufficiently high level of sensitivity and specificity to predict mortality. 


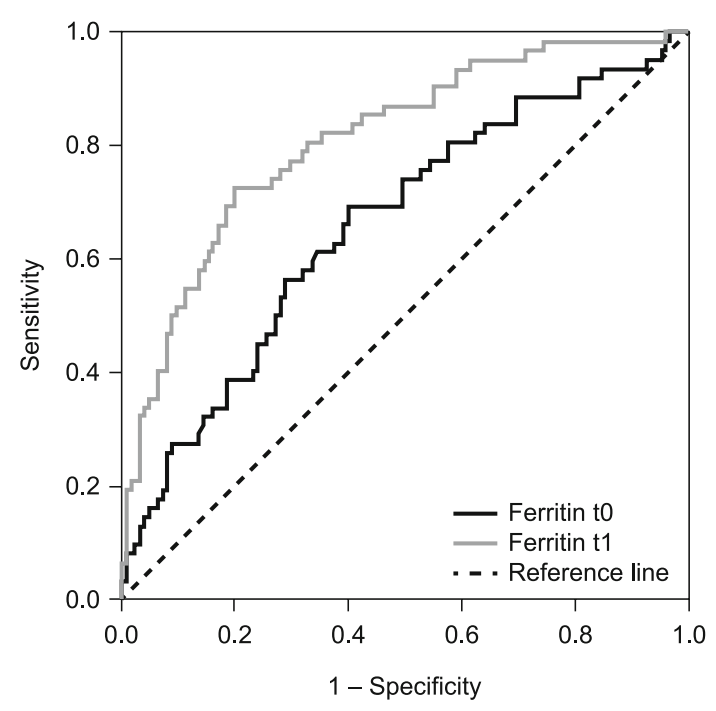

Fig. 3. ROC curve for Ferritin.

The ROC curves of D-dimer, procalcitonin, and ferritin are presented in Figures 1, 2, and 3, respectively.

\section{Discussion}

SARS-CoV-2 is responsible for one of the biggest public health problems encountered in the 21 st century. When the age and gender distribution is examined across COVID-19 patients, it has been shown in the literature that old individuals and men predominate. In the report prepared by Garg et al for the Centers for Disease Control and Prevention in the United States, it has been reported that out of 1,482 patients admitted to the hospital, $74 \%$ were above the age of 50, and $54.4 \%$ were males (5). Similarly, in our study, the mean age was higher in non-survivors as compared to patients discharged from ICUs, and the mortality rate was higher in men. Our results are consistent with the information in the literature.

COVID-19 may cause sepsis and septic shock similar to other infections. The clinical table of shock is characterized by vasodilation, hypotension, systemic vascular resistance, and hypoxia. We aimed to keep the mean arterial pressure above $65 \mathrm{mmHg}$ in our patients and preserve organ perfusion by monitoring tissue perfusion in accordance with sepsis guidelines (6). In order to maintain the hemodynamic stability, we added noradrenaline as an inotropic agent to the treatment to be given at certain intervals to all our patients.

The diagnosis of acute respiratory distress syndrome (ARDS) in our patients was made according to the Berlin Criteria (7). Lung-protective ventilation criteria [Ppeak $<25 \mathrm{cmH}_{2} \mathrm{O}$, tidal volume: $6-8 \mathrm{~mL} / \mathrm{kg}, \mathrm{pO}_{2}>60 \mathrm{mmHg}, \mathrm{SpO}_{2}>90 \%$, and driving pressure (Pplato minus positive end-expiratory pressure (PEEP) $<15)$ ] were applied (8).

Most COVID-19 patients admitted to ICU develop respiratory distress and need mechanical ventilation. In the study by Ziehr et al, it was reported that all 66 patients were intubated, one patient received non-invasive mechanical ventilation (NIMV) support, high-flow oxygen was administered to one patient, and 31 patients were brought to the prone position (9). In the study by Elharrar et al, it was observed that 6 out of 15 patients followed up in ICU tolerated the prone position when they were awake and their PO2 levels increased by $20 \%$ compared to basal values (10). Very few of our patients (approximately $20 \%$ ) were intubated because a significant portion of the bed capacity of the designated pandemic ICUs in our hospital belonged to the second level of care. The number of ICU beds in the third level of care accounted for $20 \%$ of bed capacity. The high intubation rates in the literature may result from the fact that such studies include patients in the third level of ICU care.

Elevated levels of acute phase reactants can be observed during infections. High CRP levels are observed in COVID-19 (11). Guan et al (4) reported elevated CRP levels in $60.7 \%$ of 1,099 patients. Xu et al (12) reported elevated CRP levels in $42 \%$ of 90 patients. In our study, CRP levels were found to be high in almost all patients. In non-survivors, CRP levels were high and the difference in CRP levels was statistically significant between nonsurvivors and patients discharged from ICUs.

D-dimer levels are also found to be high during the course of COVID-19 (11). It has been reported that D-dimer levels can help determine the disease severity in adult COVID-19 patients. Gao et al compared the laboratory parameters in patients with clinically mild and severe disease and found that D-dimer levels were statistically significantly higher in severely ill patients (13). In the study by Zhou et al, D-dimer values were found to be approximately nine times higher in non-survivors. It has been predicted that D-dimer values higher than $1 \mu \mathrm{g} / \mathrm{ml}$ may help identify patients with poor prognosis at an early stage (14). In our study, D-dimer values on day 1 were not significantly different between non-survivors and discharged patients. However, D-dimer values on day 7 were found to be higher in non-survivors when the two groups were compared. There was a statistically significant difference in day-7 D-dimer levels between the discharged patients and non-survivors. D-dimer levels were higher in non-survivors. Our results are consistent with information in the literature.

Although there are many biomarkers that can be used in the diagnosis and follow-up of sepsis in ICU, none of such parameters has sufficient sensitivity or specificity to be used alone in routine clinical practice. Although procalcitonin and CRP are the most widely used biomarkers, their effectiveness in predicting the prognosis in sepsis is limited. Considering the complex pathophysiology of sepsis, making a rapid diagnosis does not seem possible today by using a single ideal biomarker (15).

In our study, procalcitonin levels were found to be significantly higher in non-survivors compared to discharged patients. The sensitivity and specificity of cut-off values above 0.2035 and 0.2735 for days 1 and 7, respectively, were found to be high. In a study conducted by Wang et al on 138 patients, median values of laboratory parameters were compared in patients treated in either ICU or inpatient units. Procalcitonin levels higher than $0.05 \mathrm{ng} /$ $\mathrm{mL}$ were found in $49 \%$ of all patients (16). When not used alone but evaluated together with the clinical condition of the patient 
805-810

and other laboratory parameters, procalcitonin levels will be useful for predicting the prognosis of COVID-19, similarly to their use in bacterial infections. In a retrospective cohort study conducted by Tahtasakal et al, the cut-off value for procalcitonin was found to be $>0.21 \mathrm{ug} / \mathrm{L}$ in COVID-19 patients. The authors reported that high procalcitonin levels had a predictive value (17). Our results are consistent with the results of the study conducted by Tahtasakal et al.

In our study, ferritin levels were found to be significantly higher in non-survivors compared to discharged patients. Similarly, Henry BM et al found higher ferritin levels in non-survivors in a cohort study (18). Again, in a study conducted in China, it was emphasized that the follow-up of ferritin levels may be useful in predicting non-survivors (19). In our study, it was determined that sensitivity of the cut-off values $>327.5 \mathrm{ng} / \mathrm{mL}$ and $>577 \mathrm{ng} / \mathrm{mL}$ for ferritin on days 1 and 7, respectively, was significantly associated with moderate-high mortality.

Our study had some limitations. Because the study had a retrospective design, the intensive care scoring systems such as SOFA, APACHE-II, or Charlson comorbidity index could not be evaluated. It was not possible to compare the specificity of D-dimer, procalcitonin, CRP, ferritin, albumin, and WBC values with the specificity of intensive care scoring systems.

\section{Conclusion}

It can be argued that the significantly high levels of procalcitonin, ferritin, and D-dimer in non-survivors in our study can be promising guiding parameters to predict mortality in COVID-19 patients. D-dimer, procalcitonin, and ferritin showed an almost high level of sensitivity and specificity in predicting mortality. Likewise, it was found that all three markers showed the same level of sensitivity and specificity in predicting mortality. D-dimer, ferritin, and procalcitonin levels are important parameters for the follow-up and estimation of prognosis in COVID-19 patients.

\section{References}

1. Eraksoy H. COVID-19 pandemic: Leaving the first four months behind. Klimik J 2020; 33 (1): 1.

2. Nemati M, Ansary J, Nemati N. Machine-learning approaches in COVID-19 survival analysis and discharge-time likelihood prediction using clinical data. Patterns (NY) 2020; 1 (5): 100074.

3. Gupta A, Madhavan MV, Sehgal K et al. Extrapulmonary manifestations of COVID-19. Nat Med 2020; 26 (7): 1017-1032.

4. Guan WJ, Ni ZY, Hu Y et al. Clinical characteristics of coronavirus disease 2019 in China. N Engl J Med 2020; 382 (18): 1708-1720.
5. Garg S, Kim L, Whitaker M et al. Hospitalization Rates and Characteristics of Patients Hospitalized with Laboratory-Confirmed Coronavirus Disease 2019-COVID-NET, 14 States, March 1-30, 2020. MMWR 2020;69.

6. Rhodes A, Evans LE, Alhazzani W et al. Surviving Sepsis Campaign: International Guidelines for Management of Sepsis and Septic Shock: 2016. Intensive Care Med 2017; 43: 304-377.

7. ARDS Definition Task Force, Ranieri VM, Rubenfeld GD, Thompson BT, Ferguson ND, Caldwell E, et al. Acute respiratory distress syndrome: the Berlin definition. JAMA 2012; 307: 2526-2533.

8. Coronavirus Disease 2019 (COVID-19) and the Lung: Chest Physicians Need to Know Turkey Respiratory Society on April 27, 2020. http://www.solunum.org.tr/TusadData/userfiles/file/EJP-EK-SAYI-COVID19-29042020.pdf.

9. Ziehr DR, Alladina J, Petri CR et al. Respiratory Pathophysiology of Mechanically Ventilated Patients with COVID-19: A Cohort Study. Am J Respir Crit Care Med 2020; 201: 1560-1564.

10. Elharrar X, Trigui Y, Dols AM et al. Use of prone positioning in nonintubated patients with COVID-19 and hypoxemic acute respiratory failure. JAMA 2020; 323: 2336-2338.

11. Zhang ZL, Hou YL, Li DT, Li FZ. Laboratory findings of COVID-19: a systematic review and meta-analysis. Scand J Clin Lab Invest 2020; 1-7.

12. Xu X, Yu C, Qu J et al. Imaging and clinical features of patients with 2019 novel coronavirus SARS-CoV-2. Eur J Nucl Med Mol Imaging 2020; 47 (5): 1275-1280.

13. Gao Y, Li T, Han M et al. Diagnostic utility of clinical laboratory data determinations for patients with the severe COVID-19. J Med Virol 2020; 92 (7): 791-796.

14. Zhou F, Yu T, Du R et al. Clinical course and risk factors for mortality of adult inpatients with COVID-19 in Wuhan, China: a retrospective cohort study. Lancet 2020; 395 (10229): 1054-1062.

15. Pierrakos C, Vincent JL. Sepsis biomarkers: a review. 2010 [cited 2020 Jun 12]. http://ccforum.com/content/14/1/R15.

16. Wang D, Hu B, Hu C et al. Clinical Characteristics of 138 Hospitalized Patients with 2019 Novel Coronavirus-Infected Pneumonia in Wuhan, China. JAMA 2020; 323( 11): 1061-1069. DOI: 10.1001/jama.2020.1585.

17. Tahtasakal CA, Oncul A, Sevgi DY et al. Could we predict the prognosis of the COVID-19 disease? J Med Virol 2021; 93: 2420-2430. DOI: 10.1002/jmv.26751.

18. Henry BM, De Oliveira MHS, Benoit S, Plebani M, Lippi G. Hematologic, biochemical and immune biomarker abnormalities associated with severe illness and mortality in coronavirus disease 2019 (COVID-19): A meta-analysis. Clin Chem Lab Med 2020; 58 (7): 1021-1028.

19. Mehta P, McAuley DF, Brown M, Sanchez E, Tattersall RS, Manson JJ. COVID-19: consider cytokine storm syndromes and immunosuppression. Lancet 2020; 395 (10229): 1033-1034. doi.org/10.1016/S01406736(20)30628-0. 